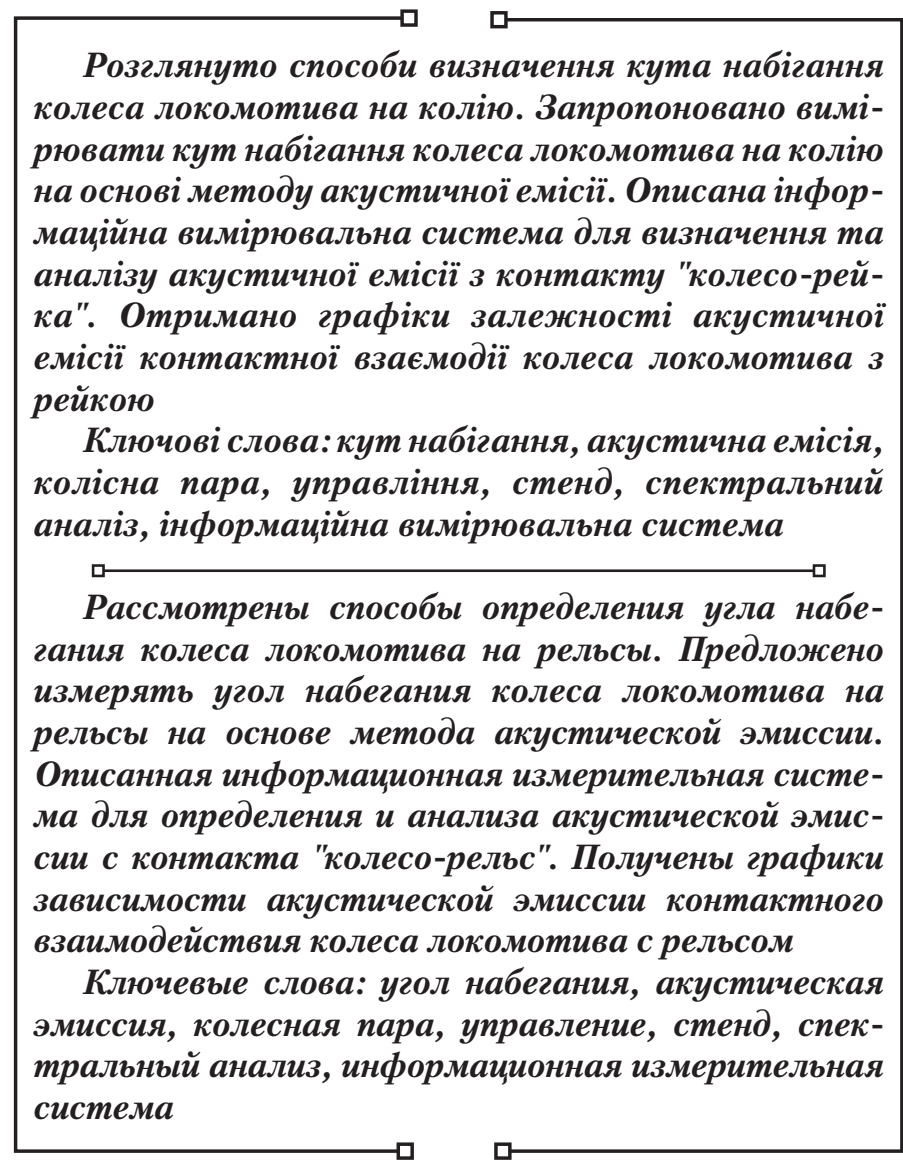

UDC 629.4.018

DOI: $10.15587 / 1729-4061.2018 .122131$

\section{EXPERIMENTAL STUDY OF THE METHOD OF LOCOMOTIVE WHEEL- RAIL ANGLE OF ATTACK CONTROL USING ACOUSTIC EMISSION}

\author{
S. KIiuiev \\ $\mathrm{PhD}$ \\ Department of logistics management and \\ traffic safety in transport \\ Volodymyr Dahl East Ukrainian \\ National University \\ Tsentralnyi ave., 59-a, \\ Severodonetsk, Ukraine, 93406 \\ E-mail: sergistreet@gmail.com
}

\section{Introduction}

The increasing volume of freight traffic and the increase in the speed of trains increase the role of operational control of rolling stock units parameters from the point of ensuring traffic safety. The element that has the greatest effect on traffic safety is the locomotive wheel pair and its interaction with the rail track [1].

To reduce the power of the wheel flange interaction with the rail head when the locomotive moves on curved tracks, it is advisable to change the locomotive wheel-rail angle of attack by turning the wheel pairs. Controlling the position of the locomotive wheel pair is possible by means of an operational measurement of the actual wheel-rail angle of attack.

To implement such system, reliable information on the wheel-rail angle of attack is needed. Existing methods for determining the wheel-rail angle of attack without the installation of a stationary sensor on the railway track use indirect measurements to calculate the value of the angle of attack and do not reflect the processes of force interaction between the wheel and the rail. The existing methods for determining the wheel-rail angle of attack involve obtaining data in post-processing. The development of a method for the wheel-rail angle attack control will allow developing a system for automatic control of the wheel pair position in the rail track, thereby improving the quality of control, safety of movement in curved sections of the track, and reducing the wear of wheels and rails.

The existing systems for monitoring the locomotive wheel-rail angle of attack are imperfect and contain a large number of unconfigured devices and various control methods. To stimulate the work aimed at improving the existing systems for monitoring the wheel position relative to the rail, a single standard is being developed in Europe based on the developed TSI instructions.

The operational control of motion parameters is possible with the help of non-destructive testing systems [2]. One of the most important tasks of the non-destructive testing system is obtaining objective information about the current state of the material of structures and about the deviation of the operation of mechanisms or technological processes from normal modes in real time. Recently, the method of acoustic emission (AE), which can in principle be used to obtain objective information, is increasingly used [3]. The method of acoustic emission makes it possible to identify mechanical processes by their acoustic images recorded on certain frequency bands.

When the locomotive moves, the wheel interacts with the rail, resulting in the generation of acoustic emission (AE). As the stresses in the wheel-rail contact increase, numerous emission sources are activated [4].

The increase in the speed of movement of the railway rolling stock increases the dynamic component of the forces acting in the "wheel-rail" system, which leads to an unproductive waste of energy for traction and premature wear of the running parts of the locomotive and the track. Dynamic properties of the carriage in the horizontal plane and lateral wear of the wheel flange and the rail head depend on the wheel-rail angle of attack, the state of the carriage part of the locomotive, which can be effectively influenced by the automatic control of the movement of the wheel pair.

Currently, the wheel position relative to the rail is not monitored on the Ukrainian rolling stock. In Western countries, sensors of capacitive and inductive types are used to 
monitor the wheel position relative to the rail. The control is most often carried out in subways and places with increased security requirements (bridges, tunnels). In the existing systems of turning wheel pairs in the horizontal plane, the wheel-rail angle of attack is not controlled, which leads to intensive wear of the wheel and rails, a decrease in safety and stability of movement.

\section{Literature review and problem statement}

Scientific research in the field of improving the design and manufacturing technology of locomotives, as well as their interaction with the railway, are aimed mainly at improving the dynamics of locomotives and reducing frictional wear of wheel tires - as a consequence of their force interaction with rails. Among the determining factors influencing the process of wear of tires, devices for radial installation of wheel pairs in curves have been identified. They improve the contact conditions of the flange with the rails, reducing the guiding force and increasing the contact area of the flange with the rail, and thus reducing the average pressure on it, and hence the wear more than 2 times. To evaluate the wear of wheel tires, the "forecast-wear" criterion is used, in which the load on the contact and the flange-rail angle of attack are introduced. The criterion allows predicting the wear of wheel tires at the design stage and during the operation of locomotives and makes it possible to assess the wear of the wheel tires when driving along the path of any configuration, including direct ones, as well as equipping them with devices for radial installation of wheel sets in the curves [5]. However, when designing new locomotives, it is proposed to use only structural changes without controlling the locomotive wheel pair position in the rail track. Structural changes in the locomotive improve the dynamic performance, reduce the wear of the locomotive wheel flange only in curved sections of the track with a radius of curvature of more than 1,200 meters. In the curved sections of the path less than 1,200 meters, a forced rotation of the locomotive wheel pairs is necessary. To create a system of automatic rotation of a locomotive wheel pair, it is necessary to measure the locomotive wheel-rail angle of attack in real time in the driving mode.

The online wheel parameter determination system can realize contactless, dynamic and real-time measurement when the train speed is less than $5 \mathrm{~km} / \mathrm{h}$ [6]. Calculation of the wheel-rail angle of attack is possible only at speeds up to $5 \mathrm{~km} / \mathrm{h}$, which is unacceptable for the automatic control system of the wheel pair position. The online system is installed permanently and it does not allow measuring the locomotive wheel-rail angle of attack along the entire route of the locomotive. It also can not be used to create a system for the automatic turning of the locomotive wheel pair, because there is no feedback to control the angle of attack.

An alternative method of monitoring the wheel pair position in the rail track is video recording [7]. This method does not provide an operative estimate of the wheel-rail angle of attack, therefore it is not suitable for control systems of the locomotive wheel pair position in the rail track. The measurement of the locomotive wheel-rail angle of attack in the driving mode is impossible with this method, since the values are obtained in post-processing.

One of the ways to determine the wheel-rail angle of attack is according to a predetermined route and the track parameters [8]. The locomotive wheel-rail angle of attack is determined by the geometric parameters of the track, the wheelbase of the locomotive, the location of the locomotive by the navigation system with an accuracy of up to 15 meters. But this method allows you to determine the predicted approximate angle of attack and therefore is not suitable for the automatic control system in the locomotive motion mode. In this way, control is impossible because of the lack of real values of the locomotive wheelrail angle of attack.

The known method of measuring the contact forces in the wheel-rail contact allows determining the wheel-rail angle of attack by the movements of the locomotive frame and carriage $[9,10]$. This method does not take into account the rotation of the wheel pair relative to the rail and the deviation of the path, which leads to additional errors in calculating the locomotive wheel-rail angle of attack. In the curved section of the track with a radius of 350 meters, the error in measuring the locomotive wheel-rail angle of attack reaches $60 \%$.

When the locomotive passes through curved sections of the track, the wheel-rail angle of attack and the specific modes of vibration of the contacting bodies change [11, 12]. However, in these studies, there is no correlation between the wheel-rail angle of attack and vibration processes. Establishing the relationship between the locomotive wheel-rail angle of attack and vibration processes in the wheel-rail contact would allow measuring the locomotive wheel-rail angle of attack in the motion mode along the entire route.

From the literature review, it follows that the measurement of the locomotive wheel-rail angle of attack in the motion mode on the entire route was not carried out. The approximate value of the locomotive wheel-rail angle of attack in the driving mode can be obtained by passing the curved track section with a radius of more than 1,200 meters. The greatest wear of the locomotive wheel occurs when passing the curved track section with a radius less than 1,200 meters, which requires a forced rotation of wheel pairs with the measurement of the locomotive wheel-rail angle of attack in the motion mode.

\section{The aim and objectives of the study}

The aim of the paper is an experimental study of the method of the locomotive wheel-rail angle of attack control using acoustic emission.

To achieve the aim, the following tasks were set:

- to justify the use of the acoustic emission method to determine the locomotive wheel-rail angle of attack;

- to develop an information measuring system for determining the locomotive wheel-rail angle of attack in real time;

- to reveal the dependence of the acoustic emission of the contact interaction of the locomotive wheel with the rail.

\section{Materials and methods of research}

When considering the process of rail oscillations under the action of a locomotive, the impact of the dynamic load can be considered as an exciting-harmonic force [13]. In this case, the vibrational motion of the rail for simplification is represented as a rod, described by the fourth-order partial differential equation: 


$$
\frac{d^{4} y}{d x^{4}}+\frac{\rho}{\mathrm{E} \cdot \chi^{2}} \cdot \frac{d^{2} y}{d t^{2}}=F \cdot \cos \Omega
$$

where $y, x$ is the vertical and horizontal displacement of the rod points; $\rho$ is the density of the material; $E$ is the modulus of elasticity of the material; $F$ is the amplitude of the exciting force; $\Omega$ is the frequency of the exciting force; $\chi$ is the parameter connecting the cross-sectional area of the rod with the moment of its inertia.

Elastic vibrations arising during the locomotive movement on the rail represent an acoustical-vibrational process, the physical nature of which is complex and has several components. When studying the process of interaction between a railway and a locomotive, it is expedient to construct computational schemes and models in which this complex vibrational process is divided into the following separate constituent types of oscillations:

- vertical;

- horizontal transverse;

- horizontal longitudinal.

Depending on the geometric parameters of the wheel and rail, oscillations with different amplitude and frequency arise in them, which in turn depend on the resonance zones of the wheelrail dynamic system, when considering it as a mechanical oscillatory system [14].

The mathematical model of oscillations of a railway rail rigidly fixed on two supports (sleepers) is represented by the theory of oscillations of elastic rods and the string theory closely related to it. In deriving a mathematical expression describing the process of rail oscillations, a smooth transition from the wave equation of vibrations of a flexible string, which is a second-order differential equation, to the wave equation of an elastic rod rigidly fixed on fixed supports is used. In the mathematical description of rail oscillations, the wave equation of an elastic rod rigidly fixed on fixed supports is used.

To calculate a number of natural frequencies of oscillations $v$ arising in the rod, the formula [15] is used:

$$
v_{i}=\frac{\pi}{2 \cdot l_{1}^{2}} \sqrt{\frac{\mathrm{E}_{1}}{S_{1} \cdot \rho_{1}}} \cdot \beta_{i},
$$

where $l_{1}$ is the distance between the supports (the spacing interval of the railway); $I_{1}$ is the moment of inertia of the section; $\rho_{1}$ is the density of the $\operatorname{rod}[20] ; E_{1}$ is the Young's modulus; $\beta_{0}=1.505 ; \beta_{1}=2.4997 ; \beta_{n} \approx n+1 / 2(n>2) ; \beta_{i}$ are the roots of the frequency equation of the form $\cos (\pi \beta)^{*} \operatorname{ch}(\pi \beta)=1$ [21]; $S_{1}$ is the rod cross-section.

As can be seen from (2), the frequency of free oscillations of a rod fixed at both ends depends on its physical (modulus of elasticity, density) and geometric (length, moment of inertia, cross-sectional area) characteristics. It follows from expression (2) that the frequency of free oscillations of the rod depends on its physical and geometric characteristics. That is, the frequency can be defined as a function $v=f_{1}\left(l_{1}, \rho_{1}, I_{1}, E_{1}, S_{1}\right)$, therefore, changing one of these rod parameters will change the frequency (frequency spectrum) of its free oscillations.

As the angle of attack increases, the contact area shifts in the direction of motion. This displacement leads to a change in the acoustic emission spectrum and the appearance of an undesirable longitudinal component of the vertical load, and as a result, an additional destabilizing moment appears that acts in the horizontal plane. The flange contact of the locomotive wheel flange with the rail leads to unstable driving regimes and the propagation of acoustic emission occurs predominantly in the radial direction.

With the purpose of revealing an informative sign of the wheel-rail angle of attack, an analysis of the investigated spectrum of acoustic emission is performed.

The investigated acoustic emission spectrum is the total acoustic signal from the wheel pair and rail, generated depending on the roughness of the wheel pair, rail roughness, contact force interaction, and vibration processes in wheelrail contact. The investigated spectrum of acoustic emission is the total acoustic signal from the contact force interaction between the wheel and the rail. The scheme for the formation of acoustic emission from the wheel-rail contact when the

locomotive moves is shown in Fig. 1. 


$$
\begin{aligned}
& A_{0}=2 t_{i} \cdot U_{0} \cdot f_{i} ; \\
& A_{0}=\frac{2 t_{i}}{T}=2 \cdot f_{1} \cdot t_{i} \cdot U_{0}\left[\sin \frac{\left(\omega_{v} t_{i}\right)}{\omega_{v} \frac{t_{i}}{2}}\right] ;
\end{aligned}
$$

$f_{1}=\frac{1}{T}-$ base frequency or repetition rate; $v_{i}-$ variable index.

Coefficient $B_{v}=0$, since the function $s(t)$ is even, i. e. $s(t)=s(-t)$.

The slip area corresponds to the function [17]:

$$
S(t)=U_{0}\left(1-\frac{1}{T}\right)
$$

$0<t<T$;

$$
\frac{A_{0}}{2}=\frac{U_{0}}{2}
$$$$
A_{V}=0 .
$$$$
B_{V}=\frac{2 U_{0}}{T}=\int_{0}^{T} \frac{T-t}{T} \sin \left(\omega_{V} t\right) \mathrm{d} t=\frac{U_{0}}{v \pi} .
$$

Coefficient $B_{V}$ decreases inversely proportional to the number of the harmonic.

From the values of the transverse acceleration spectral density power of the wheels and the sound pressure level, the following classification of acoustic emissions is defined:

- the wheel and the rail are in the stable operating mode, there is no shrieking: the noise level is less than $80 \mathrm{~dB}$;

- wheel and rail wheel vibrations increase, the noise from the rail wheel is predominantly at $1,490 \mathrm{~Hz}$, the lateral displacement is $80 \div 90 \mathrm{~dB}$;

- the wheel is in an unstable operating mode, the noise from the wheel is predominantly at a frequency of $1,090 \mathrm{~Hz}$, the sound pressure level is $90 \div 110 \mathrm{~dB}$.

The level of sound pressure from rolling increases with increasing speed, in proportion to the logarithm of speed [18]:

$$
P_{p}=P_{v 0}+N \cdot \lg \left(\frac{V}{V_{0}}\right)
$$

where $V_{0}$ is the speed of motion; $P_{v 0}$ is the sound pressure level at speed.

The speed is determined from the baseline linear regression measurements and usually takes $\mathrm{N}$ values in the range of 25 to 35 , in the calculations it is assumed to be 30 .

With the double increase in speed, it corresponds to an increase in the sound pressure level by $8 \div 10 \mathrm{~dB}$.

\section{Results of studies of the method of the locomotive wheel-rail angle of attack control}

On the basis of experimental studies [19], it can be concluded that the level of sound pressure emitted from undamped wheels increases in proportion to the speed of movement and the angle of attack. Squealing disappears completely when the wheel flange comes into contact with the side surface of the rail.

The formula (6) for the dependence of the sound pressure level on speed is used in the analysis of acoustic emission from the wheel-rail contact and the estimation of the wheelrail angle of attack.

The possibility of using acoustic emission to determine the wheel-rail angle of attack is considered, based on the methods and algorithm for analyzing the acoustic emission spectrum for determining the frictional conditions of contacting, when creating an automatic lubrication system for contacting surfaces [20]. The algorithm for analyzing the acoustic emission spectrum for determining the frictional conditions of contact between the locomotive wheel and the rail is taken as the basis for processing the experimental data obtained from the rolling station.

With the purpose of revealing an informative sign for determining the angle of attack, experimental studies of acoustic emission from the wheel-rail contact under various interaction conditions have been carried out. As a result of experimental studies, it was revealed that the acoustic emission spectrum is not uniform, at some frequencies the sound pressure level significantly exceeds the equivalent sound pressure level. According to experimental data, graphs of the frequency change in the sound pressure level for different types of interaction (the level of sound pressure from impact interaction, flange interaction and rolling) are obtained (Fig. 3).

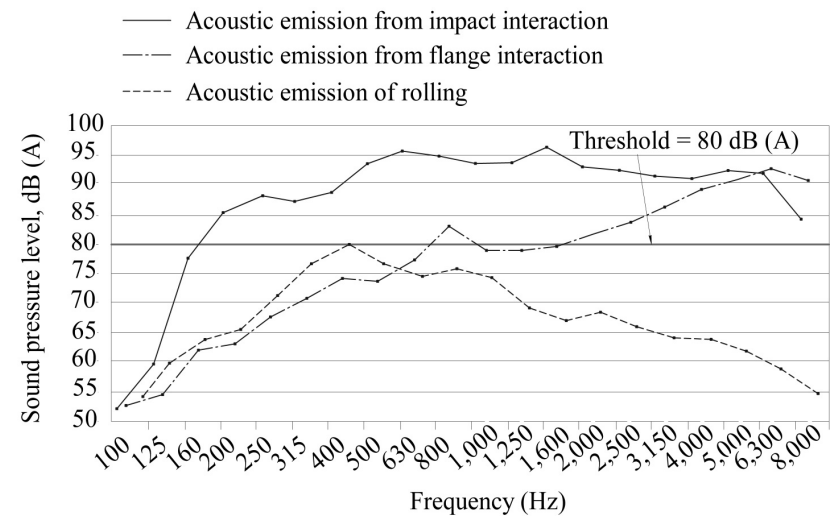

Fig. 3. Graph of dependence of acoustic emission of wheel-rail contact interaction

The flange contact can be uniquely identified by the sound pressure level in the frequency range from 800 to 4,000 Hz.

The analysis of acoustic emission is shown in Table 1.

The type of wheel-rail contact interaction is determined by the coefficient:

$$
k_{k}=\frac{\sum_{i=k}^{N} P_{0}^{2} 10^{L_{(i)} / 10}}{\sum_{i=l}^{N} P_{0}^{2} 10^{L_{(i)} / 10}} \cdot 100 \%,
$$

where the numerator is the power of the $\mathrm{AE}$ in the frequency range $(2,000 \div 10,000)$, and the denominator is the power of the $\mathrm{AE}$ in the entire frequency range.

Depending on the value, the type of contact interaction is determined (Tables 1, 2).

For the purpose of determining the wheel-rail angle of attack, an acoustic emission test is conducted under various conditions of mutual installation of the wheel and rail. Experimental studies of acoustic emission were performed using an improved field roller stand [21]. The scheme of the stand is shown in Fig. 4. 
Table 1

Analysis of acoustic emission from the wheel-rail contact interaction

\begin{tabular}{|c|c|c|c|c|c|}
\hline \multicolumn{2}{|c|}{ Parameters of AE } & AE from rolling & AE from creep & $\begin{array}{c}\text { AE from flange } \\
\text { interaction }\end{array}$ & $\begin{array}{c}\text { AE from impact } \\
\text { interaction }\end{array}$ \\
\hline $\begin{array}{c}\text { The value in the frequency } \\
\text { band to the peak }\end{array}$ & Frequency $(\mathrm{Hz})$ & 315 & 5,000 & 4,000 & 1,000 \\
\cline { 2 - 6 } & $\mathrm{P}(\mathrm{dBA})$ & 88.6 & 90.1 & 95.3 & 95.8 \\
\hline $\begin{array}{c}\text { The value at peak } \\
\text { frequency }\end{array}$ & Frequency $(\mathrm{Hz})$ & 400 & 6,300 & 5,000 & 1,250 \\
\cline { 2 - 6 } & $\mathrm{P}(\mathrm{dBA})$ & 91.1 & 111.1 & 101.9 & 99.7 \\
\hline $\begin{array}{c}\text { The value in the frequency } \\
\text { band after the peak }\end{array}$ & Frequency $(\mathrm{Hz})$ & 500 & 8,000 & 6,300 & 1,600 \\
\cline { 2 - 6 } & $\mathrm{P}(\mathrm{dBA})$ & 88.4 & 86.9 & 97.5 & 92.4 \\
\hline \multirow{2}{*}{$\begin{array}{c}\text { Difference in sound } \\
\text { pressure level }\end{array}$} & $\Delta_{1}$ & 2.5 & 21 & 6.6 & 3.9 \\
\cline { 2 - 6 } & $\Delta_{2}$ & 2.7 & 24.2 & 4.4 & 7.3 \\
\hline
\end{tabular}

Notes: $P$ is the sound pressure level; $\Delta_{1}$ is the difference in the sound pressure level at the dominant frequency and before the dominant frequency; $\Delta_{2}$ is the difference in the sound pressure level at the dominant frequency and after the dominant frequency

Table 2

Type of wheel-rail contact interaction

\begin{tabular}{|c|c|c|}
\hline AE from rolling & AE from impact & $\begin{array}{c}\text { AE from flange } \\
\text { interaction }\end{array}$ \\
\hline$k_{k}=0.0499$ & $k_{k}=0.3211$ & $k_{k}=0.9064$ \\
\hline
\end{tabular}

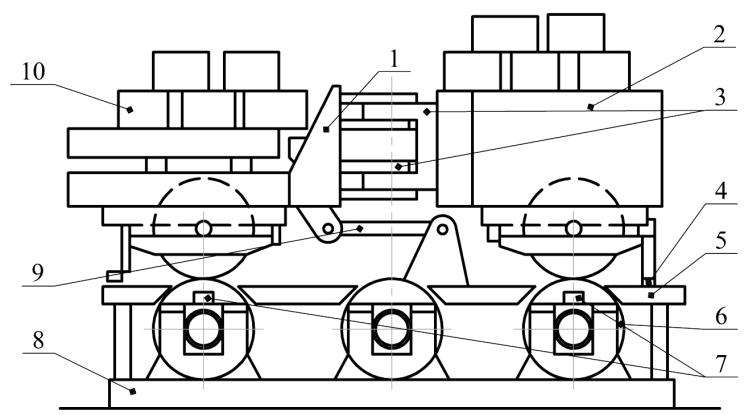

Fig. 4. Scheme of the roller stand: 1 - the semi-frame of the rigid wheel pair (RWP), 2 - the semi-frame of the elastic wheel pair (EWP), 3 - the pivot connection to the carriage half-frames, 4 - the guide device with the force sensor, 5 - the rails (imitation), 6 - support rollers, 7 - sensors for lateral movements of wheel pairs of EWP and RWP,

8 - track roller frame, 9 - articulated rod holding experienced carriage on a roller stand, 10 - ballast plates for loading an experienced carriage, weight of one plate is $3.5 \mathrm{t}$

The layout of the measuring equipment is shown in Fig. 5.

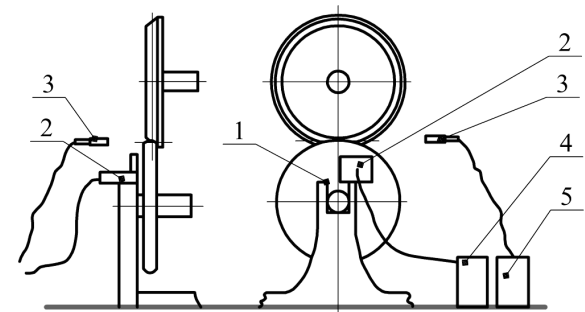

Fig. 5. The layout of the measuring equipment: 1 - stand roller magnet, 2 - speed sensor, 3 - microphone, 4 - analog-digital card, 5 - sound level meter

Experimental measurements were carried out under the condition of a dry frictional state of the wheel-rail contact. The range of variable parameters of the wheel pair movement:

- wheel-rail angle of attack 0.0; 0.20...1.50;

- speed of the wheel pair at 10 and $15 \mathrm{~m} / \mathrm{s}$ in the traction mode;

- vertical load on the wheel $110 \mathrm{kN}$;

- relative slip not more than $1.5 \%$.

The acoustic emission study was performed using the SoundRuler software [22, 23].

Examples of processed data using the SoundRuler tool for different angles of attack are shown in Fig. 6. The graphs show that the maximum values of the sound pressure level are located in the frequency range from 200 to $300 \mathrm{~Hz}$. The maximum deviation of the sound pressure level from the equivalent sound pressure level varies depending on the angle of attack.
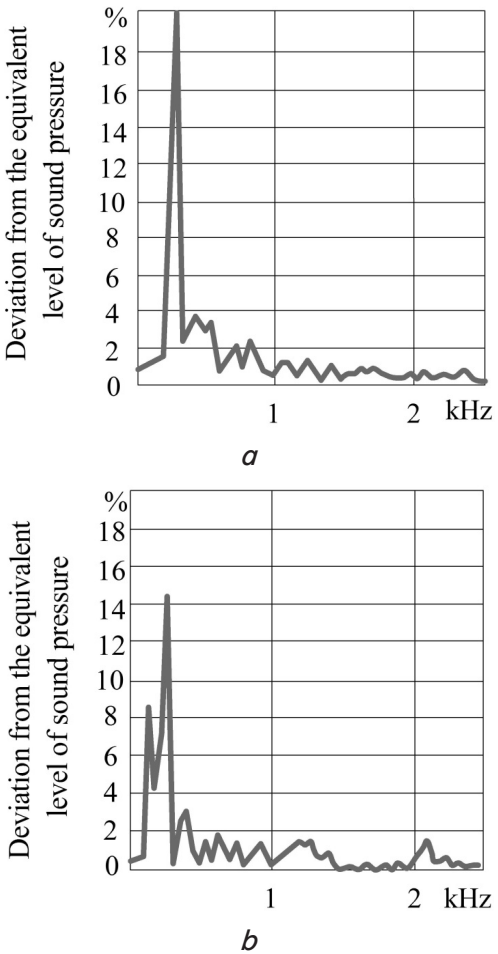

Fig. 6. Results of spectral analysis of $A E$ from the wheel-rail contact for a speed of $15 \mathrm{~m} / \mathrm{s}: a-$ angle of attack of $0 \mathrm{mrad} ; b-$ angle of attack of $3.5 \mathrm{mrad}$

The analytical dependence of the deviation of the sound pressure level on the dominant frequency from the equiva- 
lent level at different wheel-rail angles of attack is described by a third-order polynomial:

$$
\phi_{i j}\left(P_{0}\right)=0.0001 \cdot P_{0}^{3}-0.002 \cdot P_{0}^{2}+0.0602 \cdot P_{0}+0.1206,
$$

where $\phi_{i j}\left(P_{0}\right)$ is the wheel-rail angle of attack, mrad; $P_{0}$ is the level of sound pressure from the "wheel-rail" contact at the dominant frequency, $\mathrm{dB}$.

\section{Discussion of results of the study of the angle of attack measurement by acoustic emission}

The obtained results confirmed the assumptions that the acoustic emission spectrum changes with changing the wheel-rail angle of attack.

In the frequency range from 200 to $300 \mathrm{~Hz}$, the maximum deviation of the sound pressure level from the equivalent sound pressure level is observed. By the magnitude of the maximum deviation from the equivalent sound pressure level at the indicated frequencies, it is possible to measure the value of the wheel-rail angle of attack.

Based on the results obtained, we come to the conclusion that it is possible to determine the angle of attack by the method of acoustic analysis. The estimation of the angle of attack is carried out using a special algorithm for processing information, which is received from a microphone directed to the wheel-rail contact. According to this algorithm, in the discrete mode, the maximum deviation of the sound pressure level from the equivalent level for these frequencies is obtained. According to the obtained values, the locomotive wheel-rail angle of attack is determined in accordance with the established analytical dependence of the deviation of the sound pressure level at the dominant frequency from the equivalent level.

Due to the non-contact measurement of the locomotive wheel-rail angle of attack in the driving mode, it becomes possible to monitor the angle of attack.

The results of the experimental research obtained on the field roller stand can also be used on the locomotive. However, to fully assess the adequacy of the obtained dependencies, an experimental check on the locomotive is necessary.

The obtained dependence of the sound pressure level on the wheel-rail angle of attack can be used in the synthesis of the automatic control system for the wheel pair position in the rail track.

Studies of acoustic emission at the roller stand, where the rail is replaced by a roller, are a continuation of the research on the stand with two rollers. Further studies of acoustic emission on the locomotive should be performed. If the wheel pair can be rotated relative to the roller on the roller stand and the angle of attack is measured or set, then to measure the locomotive wheel-rail angle of attack, it is necessary to install sensors along the railroad track. And after that, already to carry out experimental studies that are costly and time-consuming to install sensors and conduct a series of experiments. In addition, in order to obtain all the values of the locomotive wheel-rail angles of attack and the corresponding deviations in the sound pressure level, curved sections of the track with a radius of 150 meters to 2,000 meters are necessary.

\section{Conclusions}

1. It has been established that the level of sound pressure emitted from undamped wheels increases in proportion to the speed of movement and the angle of attack. A double increase in the locomotive speed corresponds to an increase in the sound pressure level from the wheel-rail contact by $8 \div 10 \mathrm{~dB}$. The study of the acoustic emission spectrum from the wheel-rail contact was carried out by dividing into four groups: acoustic emission of rolling, acoustic emission as a result of impacts, squealing, shrieking. Due to the separation of the AE into groups, it was found that the wheel is in an unstable operating mode, mainly at a frequency of $1,090 \mathrm{~Hz}$ and an acoustic pressure level of $90 \div 110 \mathrm{~dB}$.

2. The estimation of the angle of attack is carried out with the help of a well-known algorithm for processing information, which is received from a microphone directed to the wheel-rail contact. The information measuring system in discrete mode processes acoustic emission from the wheelrail contact and sends the values of the maximum deviation of the sound pressure level from the equivalent level in the frequency range from 200 to $300 \mathrm{~Hz}$. By the values of the maximum deviation of the sound pressure level from the equivalent level, it is possible to determine the locomotive wheel-rail angle of attack according to the analytical dependence:

$$
\phi_{i j}\left(P_{0}\right)=0.0001 \cdot P_{0}^{3}-0.002 \cdot P_{0}^{2}+0.0602 \cdot P_{0}+0.1206 \text {. }
$$

3. It is established that the dominant frequency of the acoustic emission from the wheel-rail contact in the driving mode is $200 \ldots 300 \mathrm{~Hz}$. The obtained analytical dependence of the sound pressure level on the wheel-rail angle of attack can be used when creating an automatic wheel pair steering system.

\section{References}

1. Kliuiev S. O. Pidvyshchennia bezpeky rukhu na zaliznytsi // Visnyk SNU im. V. Dalia. Sievierodonetsk. 2016. Issue 1 (225). P. $104-107$.

2. Kliuiev S. O. Analiz metodiv identyfikatsiyi zaliznychnoho rukhomoho skladu // Visnyk SNU im. V. Dalia. 2017. Issue 3 (233). P. 85-89.

3. Kudinov D., Shaydurov G. Non-contact nondestructive rail testing // 2009 International Siberian Conference on Control and Communications. 2009. doi: 10.1109/sibcon.2009.5044873

4. Shapran E. Primenenie metoda akusticheskoy emissii dlya issledovaniya processa formirovaniya scepnyh harakteristik kontakta koleso - rel's // Vestnik VNIIZHT. 2005. Issue 5. P. 31-35.

5. Masliev V. G. Osobennosti dinamiki rel'sovyh ekipazhey s ustroystvami dlya radial'noy ustanovki kolesnyh par v krivyh // Mekhanika ta mashynobuduvannia. 1999. Issue 1. P. 161-165. 
6. Online detection system for wheel-set size of rail vehicle based on 2D laser displacement sensors / Xing Z., Chen Y., Wang X., Qin Y., Chen S. // Optik - International Journal for Light and Electron Optics. 2016. Vol. 127, Issue 4. P. 1695-1702. doi: 10.1016/ j.ijleo.2015.11.053

7. Kim M.-S. Measurement of the wheel-rail relative displacement using the image processing algorithm for the active steering wheelsets // International journal of systems applications, engineering and development. 2012. Vol. 6, Issue 1. P. 114-121.

8. Simson S., Cole C. Control alternatives for yaw actuated force steered bogies // IFAC Proceedings Volumes. 2008. Vol. 41, Issue 2. P. 8281-8286. doi: 10.3182/20080706-5-kr-1001.01400

9. A new measuring method of wheel-rail contact forces and related considerations / Matsumoto A., Sato Y., Ohno H., Tomeoka M., Matsumoto K., Kurihara J. et. al. // Wear. 2008. Vol. 265, Issue 9-10. P. 1518-1525. doi: 10.1016/j.wear.2008.02.031

10. Kalivoda J., Bauer P. Roller Rig Tests with Active Stabilization of a Two-Axle Bogie // Proceedings of the Third International Conference on Railway Technology: Research, Development and Maintenance. Civil-Comp Press, Stirlingshire, United Kingdom, 2016. doi: $10.4203 /$ ccp.110.96

11. Thompson D., Jones C. Noise and vibration from the wheel-rail interface // Wheel-Rail Interface Handbook. 2009. P. 477-509. doi: 10.1533/9781845696788.1.477

12. Effect of the wheel/rail contact angle and the direction of the saturated creep force on rail corrugation / Cui X. L., Chen G. X., Yang H. G., Zhang Q., Ouyang H., Zhu M. H. // Wear. 2015. Vol. 330-331. P. 554-562. doi: 10.1016/j.wear.2014.12.046

13. Kudinov D. S., Shaydurov G. Ya. Problemy nerazrushayushchego kontrolya rel'sovyh putey na zheleznodorozhnom transporte // Datchiki i Sistemy. 2009. Issue 10. P. 19-27.

14. Kudinov D. S., Shaydurov T. Ya. Beskontaktnaya defektoskopiya zheleznodorozhnyh putey na osnove parametricheskoy modulyacii elektromagnitnyh voln SVCh diapazona // XV Vserossiyskaya nauchno-prakticheskaya konferenciya «Radiolokaciya, navigaciya i svyaz’». Vol. 1. Voronezh, 2010. P. 852-858.

15. Kudinov D. S., Shaydurov G. Ya. Problema distancionnogo metoda nerazrushayushchego kontrolya rel'sov na zheleznodorozhnom transporte // Sovremennye problemy radioelektroniki. Krasnoyarsk, 2008. P. 147-150.

16. Thompson D. J., Jones C. J. C. A review of the modelling of wheel/rail noise generation // Journal of Sound and Vibration. 2000. Vol. 231, Issue 3. P. 519-536. doi: 10.1006/jsvi.1999.2542

17. Nosko G. S., Koshechkina N. I. K voprosu o mekhanizme zvukoobrashchovaniya ot kontaktnogo vzaimodeystviya kolesa i rel'sa // Vestnik VNU im. V. Dalya. 2011. Issue 4 (158). P. 102-106.

18. Thompson D. J. Railway noise and vibration. Mechanisms, modeling and means of control. Elsevier, 2009. 519 p.

19. Study on using noise for development of active steering control system of rail vehicle / Spiryagin M., Lee K. S., Yoo H. H., Spiryagin V., Klyuyev S. // Proceedings of the 23nd National Conference and Exposition on Noise Control Engineering (Noise-Con 2008) (and the Sound Quality Symposium). USA: Curran Associates, Inc., 2009. P. 499-506.

20. Experimental and theoretical investigation of railway wheel squeal / Hsu S. S., Huang Z., Iwnicki S. D., Thompson D. J., Jones C. J. C., Xie G., Allen P. D. // Proceedings of the Institution of Mechanical Engineers, Part F: Journal of Rail and Rapid Transit. 2007. Vol. 221, Issue 1. P. 59-73. doi: 10.1243/0954409jrrt85

21. Stend dlia doslidzhennia vzaiemodiyi kolesa z reikoiu zaliznychnoho transportu: Pat. No. 45683 UA. MPK (2009), G01M 17/007 / Kliuiev O. S., Kliuiev S. O., Spiriahin V. I., Horbunov M. I., Ulshyn V. O., Kravchenko K. O. No. u200904393; declareted: 05.05.2009; published: 25.11.2009, Bul. No. 22.

22. The application review on the rolling stock of devices for turn of wheel pairs in the horizontal plane / Golubenko A. L., Malohatko A. A., Klyuev S. A., Klyuev A. S. // Teka. 2011. Vol. 11A. P. 5-11.

23. Kliuiev S. O. Znyzhennia znosu v systemi "koleso-reika" udoskonalennia avtomatyzatsiyi protsesu lubrykatsiyi hrebenia kolesa // Visnyk natsionalnoho universytetu "Lvivska politekhnika". Seriya: dynamika, mitsnist ta proektuvannia mashyn i pryladiv. 2017. Issue 866. P. 157-161. 